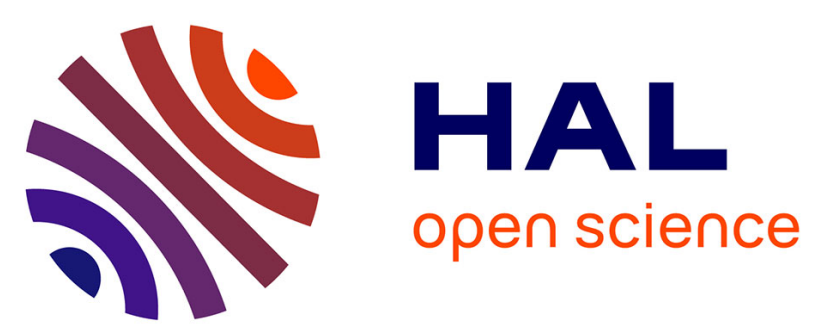

\title{
Kinetic analysis of interactions between alkylene-linked bis-pyridiniumaldoximes and human acetylcholinesterases inhibited by various organophosphorus compounds
}

Timo Wille, Fredrik Ekström, Jong-Cheol Lee, Yuan-Ping Pang, Horst Thiermann, Franz Worek

\section{To cite this version:}

Timo Wille, Fredrik Ekström, Jong-Cheol Lee, Yuan-Ping Pang, Horst Thiermann, et al.. Kinetic analysis of interactions between alkylene-linked bis-pyridiniumaldoximes and human acetylcholinesterases inhibited by various organophosphorus compounds. Biochemical Pharmacology, 2010, 80 (6), pp.941. 10.1016/j.bcp.2010.05.022 . hal-00608916

\section{HAL Id: hal-00608916 https://hal.science/hal-00608916}

Submitted on 16 Jul 2011

HAL is a multi-disciplinary open access archive for the deposit and dissemination of scientific research documents, whether they are published or not. The documents may come from teaching and research institutions in France or abroad, or from public or private research centers.
L'archive ouverte pluridisciplinaire $\mathbf{H A L}$, est destinée au dépôt et à la diffusion de documents scientifiques de niveau recherche, publiés ou non, émanant des établissements d'enseignement et de recherche français ou étrangers, des laboratoires publics ou privés. 


\section{Accepted Manuscript}

Title: Kinetic analysis of interactions between alkylene-linked bis-pyridiniumaldoximes and human acetylcholinesterases inhibited by various organophosphorus compounds

Authors: Timo Wille, Fredrik Ekström, Jong-Cheol Lee, Yuan-Ping Pang, Horst Thiermann, Franz Worek

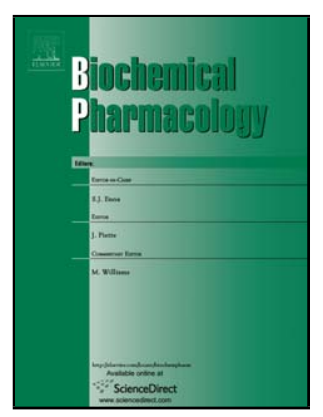

PII: S0006-2952(10)00386-2

DOI: doi:10.1016/j.bcp.2010.05.022

Reference: BCP 10577

To appear in: $\quad B C P$

Received date: $\quad 15-4-2010$

Revised date: $\quad 18-5-2010$

Accepted date: $\quad 18-5-2010$

Please cite this article as: Wille T, Ekström F, Lee J-C, Pang Y-P, Thiermann H, Worek F, Kinetic analysis of interactions between alkylene-linked bis-pyridiniumaldoximes and human acetylcholinesterases inhibited by various organophosphorus compounds, Biochemical Pharmacology (2008), doi:10.1016/j.bcp.2010.05.022

This is a PDF file of an unedited manuscript that has been accepted for publication. As a service to our customers we are providing this early version of the manuscript. The manuscript will undergo copyediting, typesetting, and review of the resulting proof before it is published in its final form. Please note that during the production process errors may be discovered which could affect the content, and all legal disclaimers that apply to the journal pertain. 


\title{
Kinetic analysis of interactions between alkylene-linked bis- pyridiniumaldoximes and human acetylcholinesterases inhibited by various organophosphorus compounds
}

\author{
Timo Wille ${ }^{1}$, Fredrik Ekström ${ }^{2}$, Jong-Cheol Lee ${ }^{3} \#$, Yuan-Ping Pang ${ }^{3}$, Horst \\ Thiermann ${ }^{1}$, Franz Worek ${ }^{1 *}$
}
${ }^{1}$ Bundeswehr Institute of Pharmacology and Toxicology, Neuherbergstrasse 11, 80937 Munich, Germany
${ }^{2}$ Swedish Defence Research Agency, CBRN Defence and Security, Umeå, Sweden
${ }^{3}$ Computer-Aided Molecular Design Laboratory, Mayo Clinic, Rochester, MN, U.S.A. \# Current address: Energy Materials Research Center, Korea Research Institute of Chemical Technology ,P.O. Box 107, Sinseongno 19, Yuseong, Daejeon 305-600, Korea.

\footnotetext{
${ }^{*}$ Corresponding author:

phone +49-89-3168-2930; fax +49-89-3168-2333

E-mail address: FranzWorek@Bundeswehr.org
} 


\section{Abstract}

The therapeutic approach of organophosphorus compound (OP) intoxications is to reactivate the inhibited enzyme acetylcholinesterase (AChE). Numerous studies demonstrated a limited efficacy of standard oxime-based reactivators against different nerve agents such as tabun and cyclosarin. This emphasizes research for more effective oximes. In the present study, reactivation kinetics of tabun-, sarin-, cyclosarin-, VX- or paraoxon-ethyl-inhibited human AChE (hAChE) with a homologous series of bis-ortho-pyridiniumaldoximes, Ortho-4 Ortho-9, was investigated with a robot-assisted setting, allowing determination of second-order reactivation rate constants as well as model calculations. The reactivation constants of Ortho-4 - Ortho-9 resulted in marked differences of affinity and reactivity depending on the OP structure and the linker length of the oximes. In general, the $K_{\mathrm{D}}$ values decreased with increasing linker length. Reactivity increased from Ortho-4 to Ortho-6 for PXE- and VX-inhibited hAChE and from Ortho-4 to Ortho-7 for GA-inhibited hAChE and decreased again with Ortho-8 and Ortho-9. In contrast, $k_{\mathrm{r}}$ decreased with increasing linker length for sarin- and cyclosarin-inhibited hAChE. In view of the pronounced decrease of $K_{\mathrm{D}}$ from Ortho-4 to Ortho-9, the $k_{\mathrm{r} 2}$ values increased with all tested OP. Hence, the ratios of $K_{l} / K_{\mathrm{D}}$ and of $K_{l} / K_{\mathrm{r} 2}$ showed that in almost all cases the affinity of Ortho-N to the native hAChE was higher than to OP-inhibited enzyme. Model calculations indicated that Ortho-6 - Ortho-9 could be superior to obidoxime in reactivating tabun-inhibited hAChE. Finally, these data emphasize the need to develop oximes with a higher selective affinity towards OP-inhibited hAChE in order to minimize possible side effects. 
Key words: Organophosphorus compounds; Acetylcholinesterase; Oxime; Reactivation; Kinetics; Structure-Activity Relationship 


\section{INTRODUCTION}

Organophosphorus compounds (OP) have been used as insecticides for pest control [1] and as chemical weapons (tabun, sarin, VX) in military conflicts and in terrorist attacks $[2 ; 3]$. The main mechanism of action of OP is a progressive inhibition of acetylcholinesterase (AChE) by phosphylation (denotes phosphorylation and phosphonylation) of its catalytic serine hydroxyl group leading to an inactive enzyme species [4]. The inability of inhibited AChE to hydrolyze the neurotransmitter acetylcholine results in an endogenous acetylcholine overflow followed by an over-stimulation of cholinergic receptors, a massive disturbance of numerous body functions, and finally in death by respiratory failure [5]. The causal therapeutic approach of OP intoxications is to use oximes as nucleophiles to remove the phosphyl moiety and to reactivate the enzyme. Numerous in vitro and in vivo studies demonstrated a limited efficacy of standard reactivators against different OP [6]. One particular challenge is the reactivation of tabun-inhibited AChE, which typically has a secondorder reactivation constant that is several orders of magnitude lower than those of other OP-inhibited AChE, e.g., sarin-inhibited AChE. This fact emphasizes the necessity to search for more effective oximes.

Recently, a homologous series of bis-ortho-pyridiniumaldoximes tethered with 4-9 methylene groups, designated as Ortho-4 - Ortho-9, has been reported as AChE reactivators with the objective of increasing the affinity to phosphorylated human AChE (hAChE), accelerating enzyme dephosphorylation, reducing the therapeutic dosage in order to minimize adverse effects and gaining the ability to counteract a broader range of OP [7]. It was shown, that with an increasing 
linker length of the oximes the affinity to echothiophate-inhibited AChE increased leading to a remarkable rise of the second-order reactivation rate constants. Now, it was tempting to analyze the reactivation kinetics of Ortho-4Ortho-9 with tabun (GA)-, sarin (GB)-, cyclosarin (GF)-, VX- and paraoxon-ethyl (PXE)-inhibited hAChE. 


\section{MATERIAL AND METHODS}

\subsection{Chemicals}

Acetylthiocholine iodide (ATCh) and 5,5'-dithio-bis-2-nitrobenzoic acid (DTNB) were obtained from Sigma (Taufkirchen, Germany) and paraoxon-ethyl (PXE) was from Dr. Ehrenstorfer GmbH (Augsburg, Germany). Sarin (GB), tabun (GA), cyclosarin (GF) and VX (>98\% by GC-MS, $1 \mathrm{H}$ NMR and 31P NMR) were made available by the German Ministry of Defence. HI 6 (98\%) was a gift from Dr. Clement (Defence Research Establishment Suffield, Ralston, Alberta, Canada). Ortho-4 - Ortho-9 were synthesized as described previously [7]. All other chemicals were from Merck (Darmstadt, Germany).

\subsection{Preparation of hemoglobin-free erythrocyte ghosts}

Hemoglobin-free erythrocyte ghosts as a source of human erythrocyte AChE were prepared according to Dodge et al. [8] with minor modifications [9]. The AChE activity was adjusted to a minimum of $9000 \mathrm{U} / \mathrm{l}$ by appropriate dilution with phosphate buffer $(0.1 \mathrm{M}, \mathrm{pH} 7.4)$. Aliquots of the erythrocyte ghosts were stored at a temperature of $-80^{\circ} \mathrm{C}$. Prior to use, ghosts were homogenized on ice with a Sonoplus HD 2070 ultrasonic homogenator (Bandelin electronic, Berlin, Germany), three times for $5 \mathrm{~s}$ with $30 \mathrm{~s}$ intervals, to achieve a homogeneous matrix for the kinetic studies. 


\subsection{Preparation of OP-inhibited hAChE}

Ghosts were incubated with a small volume $(1 \%, v / v)$ of appropriate OP concentrations (Fig. 1) for $30 \mathrm{~min}$ at $37^{\circ} \mathrm{C}$ to achieve an AChE inhibition by $>95 \%$. Thereafter, the treated samples were dialyzed (phosphate buffer, $0.1 \mathrm{M}$, $\mathrm{pH}$ 7.4) overnight at $4^{\circ} \mathrm{C}$ to remove residual inhibitor. Then, the absence of inhibitory activity was tested by incubation of treated and control ghosts (30 min, $\left.37^{\circ} \mathrm{C}\right)$.

\subsection{Reactivation kinetics}

Reactivation kinetics was conducted according to Worek et al. [10]. The liquid handling steps of the reactivation tests were done with a Tecan Freedom EVO, for details see [11]. Tests with this robot-assisted setting were done to allow high reproducibility and ensure minimal error probability. In brief, the time- and concentration-dependent reactivation of OP-inhibited hAChE by oximes was tested with Ortho-4 - Ortho-9 $\left(1-100 \mu \mathrm{M}, 37^{\circ} \mathrm{C}\right.$; Fig. 1) in a 96-well using a discontinuous reactivation method. At specified time intervals $(0,1,10,20,30$ min) $10 \mu \mathrm{l}$ aliquots were taken and transferred to a tempered measuring plate (24-well) pre-filled with $2400 \mu$ I TRIS-DTNB buffer $\left(37^{\circ} \mathrm{C}\right)$ and $50 \mu$ ITCh $(0.65$ $\mathrm{mM}$ final concentration). This resulted in a 160 -fold dilution of AChE and oxime (final concentration of $0.00385 \mu \mathrm{M}, 0.0385 \mu \mathrm{M}$ and $0.385 \mu \mathrm{M}$ for $1 \mu \mathrm{M}, 10 \mu \mathrm{M}$ and $100 \mu \mathrm{M}$ oxime during incubation, respectively). Subsequently, the activity of the enzyme was recorded by a Safire ${ }^{2}$ spectrophotometer (TECAN, Männedorf, Switzerland). The enzyme activities were referred to control hAChE activities in the presence of the respective oxime concentration resulting in identical oxime 
concentration in the reactivation and control assay and are given as \%reactivation. The observed first-order rate constant of reactivation $k_{\text {obs }}$ was calculated for each oxime concentration by linear regression analysis applying the equation 1 . All curves fitted a $R^{2} \geq 0.98$ :

$\ln \frac{\mathrm{v}_{0}-\mathrm{v}_{\mathrm{i}}}{\mathrm{v}_{0}-\mathrm{v}_{\mathrm{t}}}=-\mathrm{k}_{\mathrm{obs}} \times \mathrm{t}$

with $v_{0}$ control activity, $v_{i}$ activity of inhibited hAChE in the absence of oxime, $v_{t}$ activity of reactivated hAChE at time $t$

$k_{\mathrm{r}}$ and $K_{\mathrm{D}}$ were obtained by the nonlinear fit of the relationship of $k_{\mathrm{obs}}$ versus oxime concentration $(1,10,100 \mu \mathrm{M})$.

The second order rate constant $k_{\mathrm{r} 2}$ describing the overall reactivating efficiency was calculated by

$$
k_{\mathrm{r} 2}=\frac{k_{\mathrm{r}}}{K_{\mathrm{D}}}
$$

\subsection{Secondary calculations}

In addition, the ratio between the inhibition constant towards native hAChE, $K_{l}$ (data taken from [7]), and the calculated $K_{\mathrm{D}}$ and $k_{\mathrm{r} 2}$ was formed. Hereby, the respective constants of Ortho-5 - Ortho-9 were referred to Ortho- 4 constants (defined as 1 ) and the relative ratios between $K_{/}$and $K_{\mathrm{D}}$ or $K_{\mathrm{r} 2}$ were calculated. 
The reactivation rate constants of Ortho-4 - Ortho-9 and obidoxime were used to calculate the time-dependent reactivations of GA-, GB-, VX-, and PXEinhibited hAChE (Eq. 3):

$$
A_{t}=A_{0} \times\left(1-e^{-k_{o b s} \times t}\right)
$$

(with $A_{t}$ hAChE activity at time $t, A_{0}$ control hAChE activity, $k_{o b s}$ first-order rate constant of reactivation).

The oxime concentration for the calculation was $50 \%$ of $K_{\mathrm{i}}$ for Ortho-4 - Ortho-9 and $10 \mu \mathrm{M}$ for obidoxime [12;13].

\subsection{Data export and statistics}

The raw data were transferred automatically via macros into Excel files and the constants and percentage of hAChE inhibition were determined with Prism 5.0 (GraphPad Software, San Diego, CA). All data are means of $n=4$ experiments. 


\section{RESULTS}

\subsection{Reversible inhibition of hAChE by Ortho-N}

It has been shown that reversible inhibition of native hAChE by Ortho-4 - Ortho-

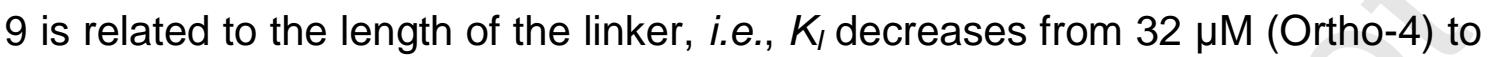
$0.3 \mu \mathrm{M}$ (Ortho-9) [7]. In this study, the reactivation of OP-inhibited hAChE by Ortho-N was determined with an oxime concentration of $1-100 \mu \mathrm{M}$ followed by extensive dilution for assaying hAChE activity. Accordingly, the final oxime concentrations during activity measurements were between 0.00385 and 0.385 $\mu \mathrm{M}$. Under these conditions, Ortho-4 - Ortho-6 did not affect the control hAChE activity. On the other hand, Ortho-7 (at $0.385 \mu \mathrm{M}$ ) reduced the activity to $76 \%$, and Ortho- 8 reduced the activity to $89 \%$ and $44 \%$ at concentrations of 0.0385 $\mu \mathrm{M}$ and $0.385 \mu \mathrm{M}$, respectively. With Ortho-9 the hAChE activity was inhibited to $64 \%$ and $15 \%$ at assay concentrations of $0.0385 \mu \mathrm{M}$ and $0.385 \mu \mathrm{M}$, respectively.

\subsection{Reactivation kinetics of Ortho-N}

The determination of reactivation rate constants of Ortho-4 - Ortho- 9 with hAChE inhibited by a number of structurally different OP (Fig. 1) resulted in marked differences of affinity (Fig. 2) and reactivity (Fig. 3). The dissociation constant progressively decreased with increasing linker length. For example, the $K_{\mathrm{D}}$ for VX-hAChE showed a 335-fold decrease when the linker length was increased from $n=4$ to $n=9$ and reached a nanomolar level with Ortho-9 (Fig. 2). Noteworthy, the differences in $K_{D}$ between different $O P$ conjugates at any 
given linker length are relatively small.

The ability of oximes to remove the phosphyl residue from the active site of the enzyme, reflected by the reactivity rate constant $k_{\mathrm{r}}$, showed marked differences among the tested OP (Fig. 3). Reactivity increased from Ortho-4 to Ortho-6 for PXE- and VX-inhibited hAChE and from Ortho-4 to Ortho-7 for GA-inhibited hAChE and decreased again with Ortho-8 and Ortho-9. In contrast, $k_{\mathrm{r}}$ decreased with increasing linker length for GB- and GF-inhibited hAChE. The highest $k_{\mathrm{r}}, 0.515 \mathrm{~min}^{-1}$, was determined with Ortho- 6 and PXE-inhibited hAChE and the largest difference in reactivity among the Ortho- $\mathrm{N}$ series was recorded with VX-inhibited hAChE (38.6-fold). Plotting the $k_{\mathrm{r}}$ of VX and PXE related to the linker length resulted in similar formed bell-shaped curves, whereas reactivation per se was higher for PXE.

The second-order reactivation rate constant $k_{\mathrm{r} 2}$ is the ratio of reactivity and affinity and is reflecting the reactivating efficiency of oximes. In view of the pronounced decrease of $K_{\mathrm{D}}$ from Ortho-4 to Ortho-9 the $k_{\mathrm{r} 2}$ values increased with all tested OP (Fig. 4). The range of $k_{\mathrm{r} 2}$ values was between $0.093 \mathrm{mM}^{-1} \mathrm{~min}^{-}$ ${ }^{1}(\mathrm{GA})$ and $75.6 \mathrm{mM}^{-1} \mathrm{~min}^{-1}(\mathrm{VX})$ and GA-inhibited hAChE showed the largest difference among the Ortho- $\mathrm{N}$ series (418-fold).

\subsection{Interaction of Ortho-N with native and OP-inhibited hAChE}

Ortho-N exhibited a positive relationship between affinity towards native or OPinhibited hAChE and linker length. Hence, it was tempting to form the ratio of $K_{l}$ / $K_{\mathrm{D}}$ and Fig. 5 shows that in almost all cases the ratio was $>1$, i.e., the affinity of Ortho-N to native hAChE was higher than the one to OP-inhibited enzyme. 
This fact is also reflected by the ratio of $K_{1} / k_{\mathrm{r} 2}$ (Fig. 6). With the exception of GA-inhibited hAChE, the ratio of $K_{l} / k_{\mathrm{r} 2}$ is always $>1$ and increasing with the linker length. Generally, increase of inhibitory potency from Ortho-4 to Ortho-9 outweighs the increase in reactivating efficiency.

\subsection{Model calculations}

In view of the relationship shown in Figs. 5 and 6 , it was compelling to calculate the time-dependent reactivation of Ortho- $\mathrm{N}$ at concentrations determined by the respective $K_{1}$. Concentrations used in these calculations were half of the $K_{\mathrm{i}}$ for the respective Ortho- $\mathrm{N}$ and $10 \mu \mathrm{M}$ for obidoxime. The data demonstrate that, under these conditions, the Ortho oximes would result in a slower reactivation of GB-, PXE- and VX-inhibited hAChE compared to obidoxime (10 $\mu \mathrm{M}$; Fig. 7). Ortho-6 - Ortho-9 would be superior to obidoxime in reactivating GA-inhibited hAChE but still would achieve only partial reactivation within a reasonable time frame. 


\section{DISCUSSION}

\subsection{Reactivation kinetics of OP-inhibited hAChE by Ortho-N}

The determination of the reactivation rate constants of Ortho- $\mathrm{N}$ revealed a relationship between linker length and affinity to hAChE inhibited by tabun (GA), sarin (GB), cyclosarin (GF), VX and paraoxon-ethyl (PXE; Fig. 2). These results are in agreement with previous findings on a continuous decrease of $K_{\mathrm{D}}$ from Ortho-3 to Ortho-9 with echothiophate-inhibited hAChE [7].

The comparison of $K_{D}$ of individual Ortho-N determined with hAChE inhibited by structurally different OP shows a rather small variation. For example, Ortho-4 Ortho- 8 the difference between the highest and lowest $K_{\mathrm{D}}$ values ranges from 2.3 to $6.0 \mu \mathrm{M}$; only with Ortho-9, a higher variation was found due to an outstanding low $K_{\mathrm{D}}$ with $\mathrm{VX}$-inhibited hAChE $(0.07 \mu \mathrm{M})$. The remarkable uniformity of the affinity of Ortho-N towards hAChE inhibited by different OP is in contrast to $K_{D}$ values determined with clinically used mono- (2-PAM) and bispyridinium oximes (obidoxime, HLö-7, HI-6, methoxime) [7;14]. For these clinically used oximes, huge differences in affinity were observed, e.g., a more than 30 - or 100 -fold difference in $K_{\mathrm{D}}$ of obidoxime or 2-PAM between cyclosarin- and sarin-inhibited hAChE, respectively. The high and uniform affinity of Ortho-oximes indicates that the binding site for this series of reactivators is compatible, on the structural level, with GA-, GB-, PXE- and VXinhibited hAChE. This conclusion is in agreement with crystallographic studies of Ortho-7, which suggested that the interaction with the peripheral anionic site 
in combination with a significant flexibility of the central linker are key factors in the ability of Ortho-7 to reactivate tabun-inhibited AChE [7;14].

The reactivity of Ortho-N with OP-inhibited hAChE was rather low compared to other oximes (Fig. 3). The only exception was the reactivation of PXE-inhibited hAChE by Ortho- 6 whose $k_{\mathrm{r}}$ was higher than the $k_{\mathrm{r}}$ values determined with methoxime, HLö 7, HI 6 and 2-PAM, although it did not reach the value of obidoxime $\left(0.81 \mathrm{~min}^{-1}\right)$ [10]. In contrast to the dissociation constant, the reactivity of Ortho-N was not related to the linker length. With PXE-, VX- and GA-inhibited hAChE, a bell-shaped curve of $k_{r}$ values was observed; while, with GB- and GF-inhibited hAChE, a gradual decrease in reactivity with increasing linker length was found. The overall reactivating efficiency of oximes is determined by the ratio of $k_{r} / K_{D}$ [10]. Predominantly due to the decrease of $K_{\mathrm{D}}$ the second-order reactivation constant $k_{\mathrm{r} 2}$ increased with the linker length (Fig. 4). The difference between Ortho-9 and Ortho-4 was moderate with GB- and GF-inhibited hAChE but with GA-inhibited hAChE a more than 400-fold difference was observed. In comparison to obidoxime, 2-PAM, HLö 7, HI 6 and methoxime [15] the Ortho- $\mathrm{N}$ exhibited a comparable or even superior reactivating efficiency. In fact, Ortho-6 had a 10-fold and Ortho-9 a 90-fold higher $k_{\mathrm{r} 2}$ than obidoxime which is considered to be one of the most effective reactivators of GA-inhibited hAChE [15]. These findings are in agreement with studies of Ortho-7, which showed a significantly higher reactivation activity than both obidoxime and HLö 7 on GA-inhibited AChE [14;16], and contradict the long standing paradigm that a para-substituted pyridiniumoxime is required for efficient reactivation of GA [17]. The underlying mechanism of the high 
reactivating efficiency of Ortho oximes with GA-inhibited AChE may be related to a differential binding in the peripheral binding site and a favourable orientation in the active-site gorge of the enzyme [14].

\subsection{Relation between intrinsic inhibitory potency and reactivation efficiency}

The therapeutic value of oximes in OP poisoning is determined by (a) the reactivating efficiency $\left(k_{\mathrm{r} 2}\right)$ with $\mathrm{hAChE}$ inhibited by a specific OP, (b) the pharmacokinetics, predicting the course of therapeutic oxime concentrations and thus determining the interval of oxime administration, (c) the intrinsic inhibitory activity of oximes towards native hAChE and (d) the tolerability. Reversible inhibition of AChE by oximes is dependent on the oxime structure and is a determinant of adverse effects and toxicity $[15 ; 18 ; 19]$.

Previously, the inhibitory potency of Ortho oximes was determined with hAChE [7] and it was shown that the affinity increased more than 100-fold from Ortho-4 to Ortho-9 and the inhibition constant $K_{l}$ was only $0.3 \mu \mathrm{M}$ with Ortho-9. These results are in line with results reported by Patocka and Bielavsky, showing a relationship between the chain length of dimeric para-oximes and the reversible inhibition [20]. Hence, the Ortho- $\mathrm{N}$ series is characterized by a positive relationship between affinity towards native or OP-inhibited hAChE and the linker length. It is therefore desirable to determine whether the increase in affinity towards OP-inhibited hAChE may be outweighed by an increase in intrinsic inhibitory potency towards the native enzyme. By forming the ratio $K_{1} /$ $K_{D}$, it became evident that, with few exceptions, the increase of affinity towards native hAChE was higher than the increase of affinity towards OP-inhibited 
hAChE, i.e., a ratio $>1$ (Fig. 5). In addition, the ratio of $K_{\mathrm{l}} / k_{\mathrm{r} 2}$ demonstrates that, with GB-, GF-, VX- and PXE-inhibited hAChE, the linker length related improvement of reactivating efficiency is outweighed by increased intrinsic inhibition (Fig. 6). These findings underscore the importance of improving reactivation efficiency by increasing mobility of the reactive oxime moiety as reported by Ekström et al. [21].

\subsection{Therapeutic use of Ortho oximes}

As a consequence of the $K_{l} / K_{D}$ ratio $>1$, the therapeutic concentration of the Ortho-N in vivo will be substantially lower compared to the clinically used oximes (2-PAM, obidoxime, $\mathrm{HI} 6$, methoxime). It has been reported that 1 $\mu \mathrm{mol} / \mathrm{kg}$ Ortho-7 was well tolerated in rats while $3 \mu \mathrm{mol} / \mathrm{kg}$ killed four of six animals [22]. Due to the high in vivo toxicity of Ortho-7 this oxime was administered at a dose of $1 \mu \mathrm{mol} / \mathrm{kg}$ to echothiophate-poisoned rats resulting in less protection compared to 2-PAM (100 $\mu \mathrm{mol} / \mathrm{kg})$.

The impact of a potentially limited concentration of Ortho- $\mathrm{N}$ on the timedependent reactivation was calculated by using the determined reactivation rate constants, therapeutic concentration of obidoxime $(10 \mu \mathrm{M})$ and concentration of Ortho-N at half of its $K_{/}$value [7]. These model calculations (Fig. 7) indicate that, due to the low concentration and subsequent low reactivity of Ortho-N, the reactivation would be markedly slower compared to obidoxime with GB-, VXand PXE-inhibited hAChE. In contrast, the high reactivating efficiency of Ortho-6 - Ortho-9 for GA-inhibited hAChE would result in a superior reactivation relative to obidoxime $(10 \mu \mathrm{M})$. On the basis of these results, it is worthy of pursuing 
pharmacokinetic studies and reactivation studies using GA-poisoned animals to properly assess the therapeutic value of Ortho- $\mathrm{N}$ in treating GA poisoning.

\subsection{Conclusions}

The reactivation kinetics of Ortho-N with hAChE inhibited by different OP is characterized by an increasing affinity proportional to the linker length, a low to moderate reactivity, and a continuous increase of reactivating efficiency from Ortho-4 to Ortho-9. At any given linker length, the difference in $K_{D}$ between this collection of OP is comparatively small. The concomitant increase of the affinity of Ortho-4 to Ortho- 9 towards native hAChE resulted in a disadvantageous ratio between intrinsic inhibition and reactivating efficiency with GB-, GF- VX- and PXE-inhibited hAChE. However, Ortho-6 - Ortho-9 showed an outstanding reactivating efficiency with GA-inhibited hAChE being up to two orders of magnitude higher compared to obidoxime. Due to the inhibitory potency towards native hAChE, the therapeutic concentration of the most effective Ortho-N will be limited and future in vivo studies are needed to assess the therapeutic value of these oximes in treating GA poisoning. Finally, these kinetic data emphasize the need to develop oximes with a more selective affinity towards OP-inhibited AChE and higher mobility for better reactivation efficiency, to minimize the adverse side effects caused by the reversible inhibition of AChE by oximes. 
Acknowledgments

Jong-Cheol Lee and Yuan-Ping Pang were supported by the US Defense Advanced Research Projects Agency (DAAD19-01-1-0322).

\section{Conflict of Interest Statement}

The authors declare that there are no conflicts of interest 


\section{References}

1. Eddleston M, Karalliedde L, Buckley N, Fernando R, Hutchinson G, Isbister $\mathrm{G}$ et al. Pesticide poisoning in the developing world - a minimum pesticides list. Lancet 2002;360:1163-7.

2. Macllwain C. Study proves Iraq used nerve gas. Nature 1993;363:3.

3. Nagao M, Takatori T, Matsuda $Y$, Nakajima M, Iwase $H$, Iwadate $K$. Definitive evidence for the acute sarin poisoning diagnosis in the Tokyo subway. Toxicol Appl Pharmacol 1997;144:198-203.

4. Marrs TC. Organophosphate poisoning. Pharmac Ther 1993;58:51-66.

5. Grob D. The manifestations and treatment of poisoning due to nerve gas and other organic phosphate anticholinesterase compounds. Arch Intern Med 1956;98:221-39.

6. Eyer P, Szinicz L, Thiermann H, Worek F, Zilker T. Testing of antidotes for organophosphorus compounds: Experimental procedures and clinical reality. Toxicology 2007;233:108-19.

7. Pang Y-P, Kollmeyer TM, Hong F, Lee JC, Hammond PI, Haugabouk SP et al. Rational design of alkylene-linked bis-pyridiniumaldoximes as improved acetylcholinesterase reactivators. Chem Biol 2003;10:491-502.

8. Dodge JT, Mitchell C, Hanahan DJ. The preparation and chemical characteristics of hemoglobin-free ghosts of human erythrocytes. Arch Biochem Biophys 1963;100:119-30. 
9. Worek F, Reiter G, Eyer P, Szinicz L. Reactivation kinetics of acetylcholinesterase from different species inhibited by highly toxic organophosphates. Arch Toxicol 2002;76:523-9.

10. Worek F, Thiermann H, Szinicz L, Eyer P. Kinetic analysis of interactions between human acetylcholinesterase, structurally different organophosphorus compounds and oximes. Biochem Pharmacol 2004;68:2237-48.

11. Wille $\mathrm{T}$, Thiermann $\mathrm{H}$, Worek $\mathrm{F}$. Development of a high-throughput screening for nerve agent detoxifying materials using a fully-automated robot-assisted biological assay. Toxicol In Vitro 2010;24:1026-1.

12. Thiermann $\mathrm{H}$, Mast $\mathrm{U}$, Klimmek R, Eyer $\mathrm{P}$, Hibler $\mathrm{A}$, Pfab $\mathrm{R}$ et al. Cholinesterase status, pharmacokinetics and laboratory findings during obidoxime therapy in organophosphate poisoned patients. Hum Exp Toxicol 1997;16:473-80.

13. Eyer $\mathrm{P}$. The role of oximes in the management of organophosphorus pesticide poisoning. Toxicol Rev 2003;22:165-90.

14. Ekström F, Pang Y-P, Boman M, Artursson E, Akfur C, Börjegren S. Crystal structures of acetylcholinesterase in complex with HI-6, Ortho-7 and obidoxime: Structural basis for differences in the ability to reactivate tabun conjugates. Biochem Pharmacol 2006;72:597-607. 
15. Eyer P, Worek F. Oximes. In: Marrs TC, Maynard RL, and Sidell FR, editors. Chemical Warfare Agents: Toxicology and Treatment. Chichester: John Wiley \& Sons Ltd., 2007. pp. 305-29.

16. Ekström F, Astot C, Pang Y-P. Novel nerve-agent antidote design based on crystallographic and mass spectrometric analyses of tabun-conjugated acetylcholinesterase in complex with antidotes. Clin Pharmacol Ther 2007;82:282-93.

17. de Jong LPA, Verhagen AAV, Langenberg JP, Hagedorn I, Löffler M. The bispyridinium-dioxime HLö-7: A potent reactivator for acetylcholinesterase inhibited by the stereoisomers of tabun and soman. Biochem Pharmacol 1989;38:633-40.

18. Calesnick B, Christensen JA, Richter M. Human toxicity of various oximes. Arch Environ Health 1967;15:599-608.

19. Marrs TC. Toxicology of oximes used in treatment of organophosphate poisoning. Adverse Drug React Toxicol Rev 1991;10:61-72.

20. Patocka J, Bielavsky J. Affinity of bis-quarternary pyridinedialdoximes for the active centre of intact and isopropylmethylphosphonylated acetylcholinesterase. Collect Czech Chem Commun 1972;37:2110-7.

21. Ekström F, Hörnberg A, Artursson E, Hammarström LG, Schneider G, Pang Y-P. Structure of $\mathrm{HI}-6^{*}$ sarin-acetylcholinesterase determined by $\mathrm{x}-$ ray crystallography and molecular dynamics simulation: Reactivator mechanism and design. PLoS One 2009;4:e5957. 
22. Hammond PI, Kern C, Hong F, Kollmeyer TM, Pang Y-P, Brimijoin S. Cholinesterase reactivation in vivo with a novel bis-oxime optimized by computer-aided design. J Pharmacol Exp Ther 2003;307:190-6. 


\section{LEGENDS}

Figure 1: Structures of OP and Ortho-N $(N=4-9)$ used in this study.

Figure 2: The dissociation constant $K_{\mathrm{D}}(\mu \mathrm{M})$ for the oxime-induced reactivation of GA-, GB-, GF-, VX-, and PXE-inhibited hAChE in dependence of the linker length of Ortho-N. The data are shown as means of 4 experiments.

Figure 3: The reactivation rate constant $k_{r}\left(\mathrm{~min}^{-1}\right)$ for the oxime-induced reactivation of GA-, GB-, GF-, VX- and PXE-inhibited hAChE in dependence of the linker length of Ortho-N. The data are shown as means of 4 experiments.

Figure 4: The calculated second-order rate constant $k_{\mathrm{r} 2}\left(\mathrm{mM}^{-1} \mathrm{~min}^{-1}\right)$ for the oxime-induced reactivation of GA-, GB-, GF-, VX- and PXE-inhibited hAChE in dependence of the linker length of Ortho-N. $k_{\mathrm{r} 2}$ was calculated by forming the ratio of $k_{\mathrm{r}}$ and $K_{\mathrm{D}}$.

Figure 5: The ratio of $K_{l} / K_{D}$ in dependence of the linker length of Ortho-N. $K_{I}$ and $K_{D}$ values of Ortho-5 - Ortho-9 were related to the respective values of Ortho-4 and the ratio of $K_{\mathrm{I}} / K_{\mathrm{D}}$ was formed with these relative constants.

Figure 6: The ratio of $K_{1} / k_{\mathrm{r} 2}$ in dependence of the linker length of Ortho oximes. $K_{\mathrm{l}}$ and $K_{\mathrm{r} 2}$ values of Ortho-5 - Ortho-9 were related to the respective values of Ortho-4 and the ratio of $K_{1} / k_{\mathrm{r} 2}$ was formed with these relative constants. 
Figure 7: Calculation of the time-dependent reactivation of GB-, GA-, PXE-, and VX-inhibited hAChE with Ortho-N or $10 \mu \mathrm{M}$ obidoxime (OBI). The concentration of the Ortho- $\mathrm{N}$ was defined as half of the respective $K_{1}$. The reactivation constants of obidoxime were taken from [10]. Please note the different scale used for the GA graph. 


\section{Figures}

Figure 1:

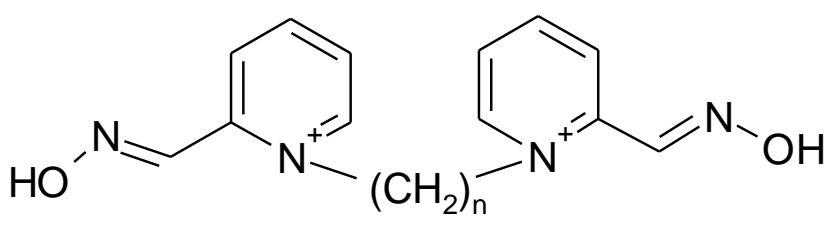

Ortho Oximes<smiles>CCOP(=O)(C#N)N(C)C</smiles>

Tabun (GA)<smiles>CC(C)OP(C)(=O)F</smiles>

Sarin (GB)<smiles>CP(=O)(F)OC1CCCCC1</smiles>

Cyclosarin (GF)<smiles>[Y]C(C)N(CCSP(C)(=O)OCC)C(C)C</smiles><smiles>CCOP(=O)(OCC)Oc1ccc([N+](=O)[O-])cc1</smiles>

Paraoxon (PXE) 
Figure 2:

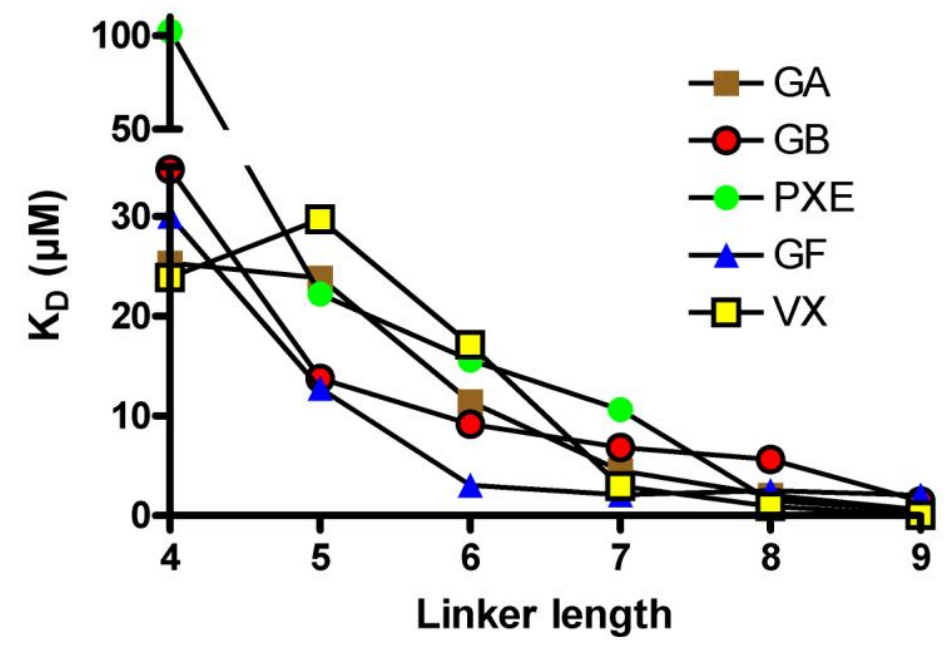


Figure 3:

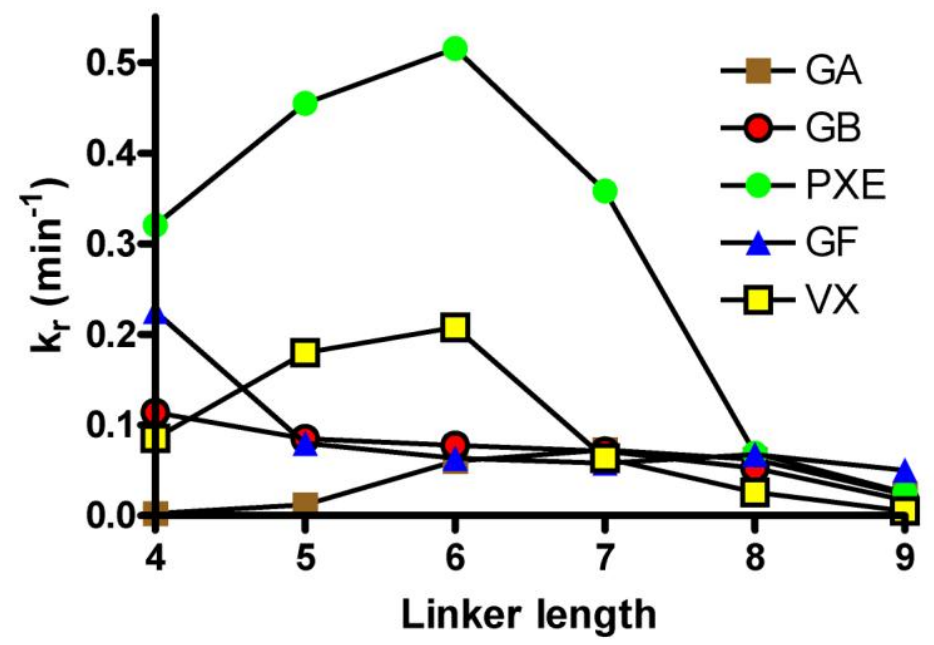


Figure 4:




Figure 5:

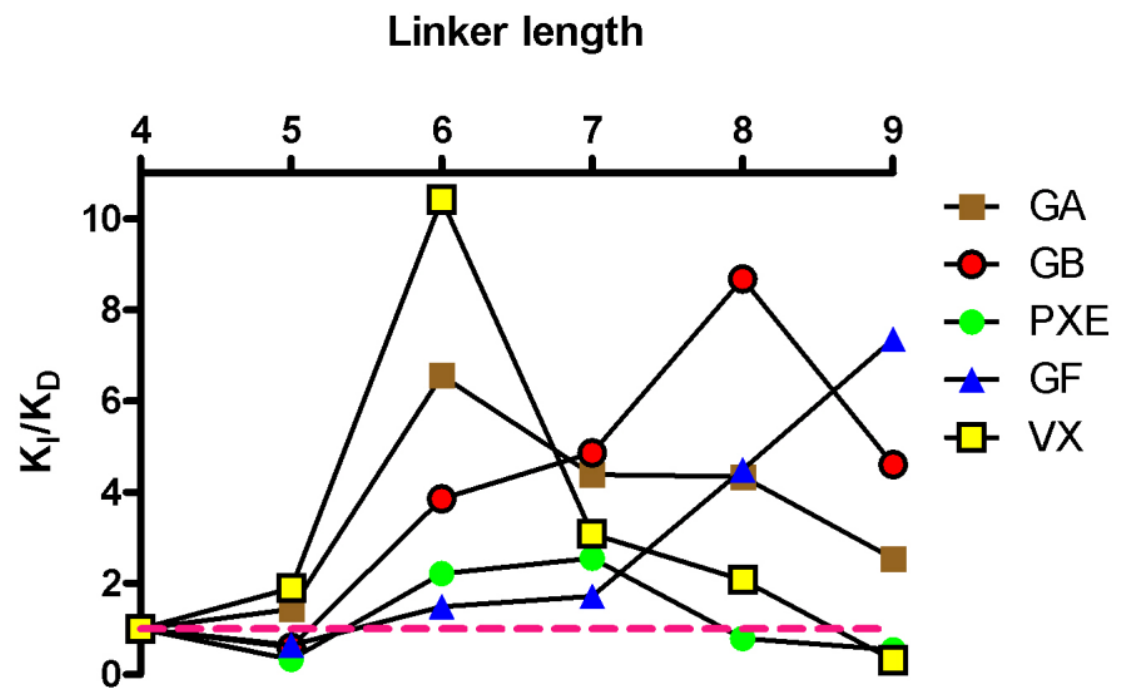


Figure 6:

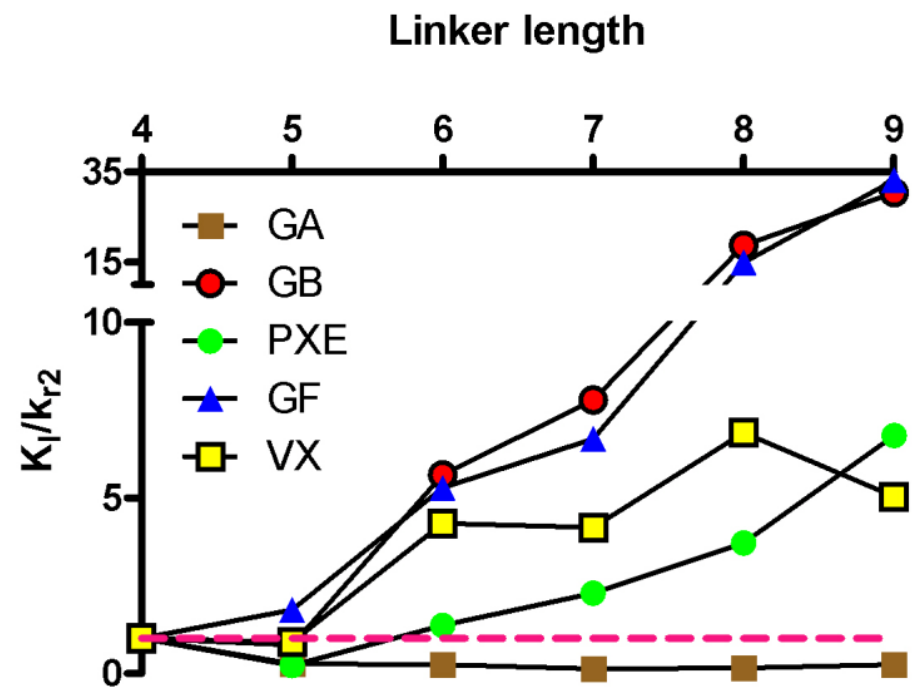


Figure 7:

GB

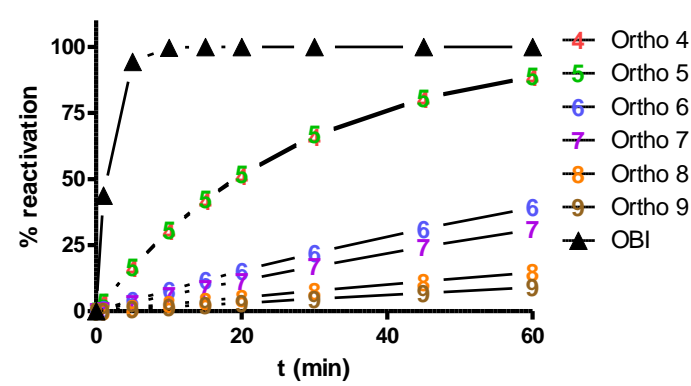

PXE



GA

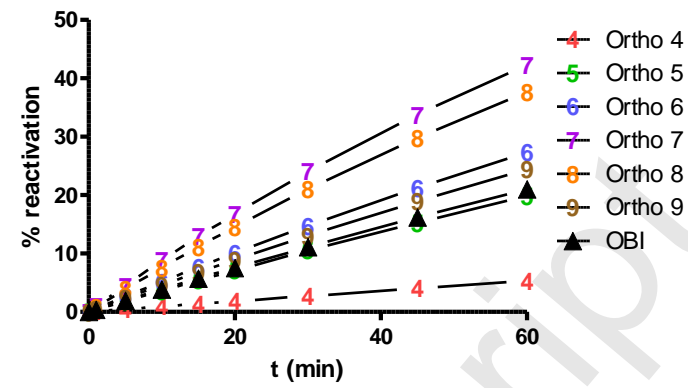

vX

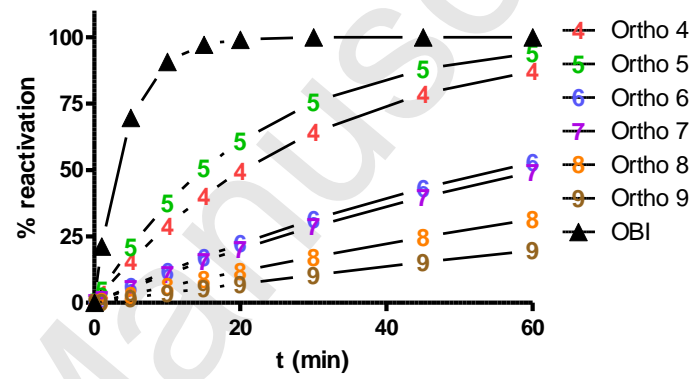


Basic structure and structure-activity-relationship of the second-order rate constant $\mathrm{k}_{\mathrm{r} 2}$ for the reactivation of OP-inhibited AChE and Ortho oxime linker length<smiles>ON=C[n+]1ccccc1CC[n+]1ccccc1/C=N/O</smiles>

Ortho Oximes

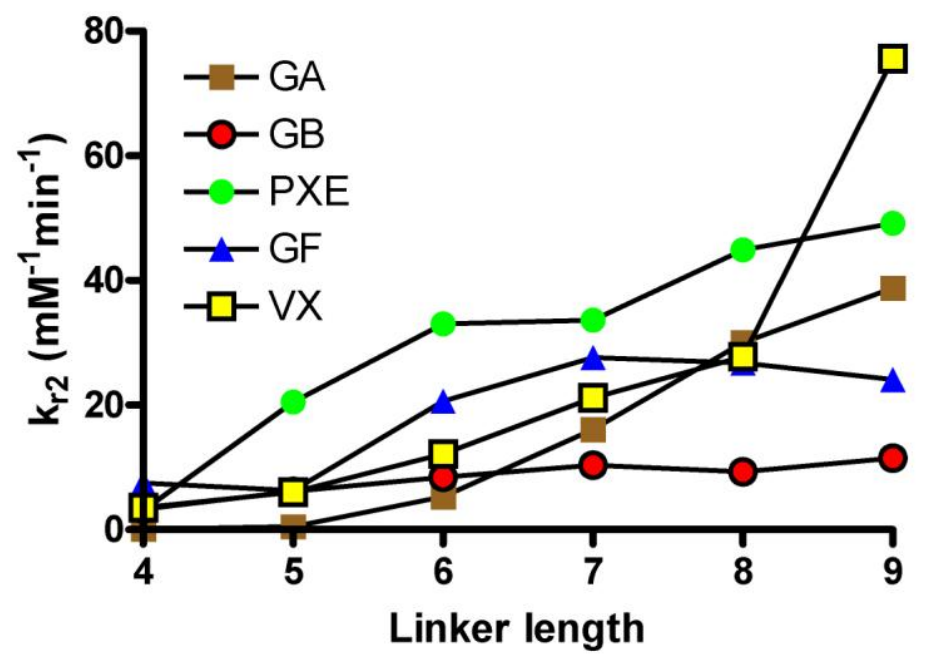

